\title{
Üniversite Öğrencilerinde Fiziksel Aktivite Düzeyi, Sedanter Davranış ve Sağlıkla İlgili Yaşam Kalitesi Arasındaki İlişkinin Araştırılması
}

\author{
Fatma YEŞIL ${ }^{*}$, Emel AVÇİN**, Asuman SALTAN***
}

$\ddot{O} \mathbf{z}$

Amaç: Bu çalışmanın amacı, üniversite öğrencileri arasında fiziksel aktivite düzeyi, sedanter davranış ve sağlıkla ilgili yaşam kalitesi arasındaki ilişkinin araştırılmasıdır.

Yöntem: Kesitsel tipte yapılan bu çalışmaya 200 üniversite öğrencisi katılmıştır. Katılımcıların \%70,5' i kadın; \%29,5' i ise erkek bireylerden oluşmaktadır. Çalışmada bireylerin fiziksel aktivite düzeylerini ölçmek için Uluslararası Fiziksel Aktivite Anketi (UFAA)-kısa form, Sağlıkla ilgili yaşam kalitelerini değerlendirmek için ise Nottingham Sağlık Profili (NSP) kullanılmıştır.

Bulgular: Bireylerin toplam fiziksel aktivite ortalaması 2772,82 $\pm 2791,92$ MET-dk/Hafta olarak belirlendi. Fiziksel aktivite toplam değeri ile yaşam kalitesi toplam değeri $(r=0,176, p=0,013)$ arasında pozitif yönde anlamlı ilişki bulundu. Oturma değeri ile yaşam kalitesi alt parametrelerinden emosyonel reaksiyon arasında pozitif yönde anlamlı ilişki $(\mathrm{r}=0,147, \mathrm{P}=0,038)$ bulunurken; ağrı ile oturma değeri arasında negatif yönde anlamlı ilişki $(r=-0,145, p=0,040)$ bulundu.

Sonuç: Bu çalışmada sağlıkla ilgili yaşam kalitesi ile fiziksel aktivite, sedanter davranış ve ağrı faktörleri arasındaki ilişki vurgulanmıştır.

Anahtar Sözcükler: Öğrenciler, sedanter yaşam tarzı, yaşam kalitesi.

The Investigation of the Relationship Between Physical Activity Level, Sedanter Behavior and Health Related Quality of Life in University Students

\begin{abstract}
Aim: The aim of this study is to investigate the relationship between physical activity level, sedentary behavior and health-related quality of life among university students.

Methods: The cross-sectional study includes 200 university students (70.5\%, women; 29.5\%, male). In the study, the International Physical Activity Questionnaire (UFAA) -short form was used to measure the physical activity levels of the individuals, and the Nottingham Health Profile (NHP) was used to evaluate their health-related quality of life.

Results: The total physical activity average of the individuals was determined as $2772.82 \pm 2791.92$ MET$\min$ / week. There was a positive significant relationship between physical activity total value and total

Özgün Araştırma Makalesi (Original Research Article)

Geliş / Received: 29.06.2021 \& Kabul / Accepted: 19.08.2021

DOI: https://doi.org/10.38079/igusabder.957314

* Öğr. Gör., Yalova Üniversitesi, Termal Meslek Yüksekokulu, Sağlık Bakım Hizmetleri Bölümü, Yaşlı Bakım Programı,

Yalova, Türkiye, E-posta: yesilhalic1985@hotmail.com ORCID https://orcid.org/o0oo-0001-6267-1596

** Öğr. Gör., Yalova Üniversitesi, Termal Meslek Yüksekokulu, Tıbbi Hizmetler ve Teknikler Bölümü, İlk ve Acil Yardım

Programı, Yalova, Türkiye, E-posta: leylifero2@gmail.com ORCID https://orcid.org/o000-0002-8867-4039

${ }_{* * *}$ Dr. Öğr. Üyesi, Yalova Üniversitesi, Sağllk Bilimleri Fakültesi, Fizyoterapi ve Rehabilitasyon Bölümü, Yalova, Türkiye, E-posta: fzt asuman@yahoo.com.tr ORCID https://orcid.org/0000-0003-0546-2610
\end{abstract}

ETİK BILLDIRIM: Çalışma, Helsinki Bildirgesi ilkelerine uygun olarak gerçekleştirilmiş olup, araştırmanın yapılabilmesi için Uludağ Üniversitesi Girişimsel Olmayan Klinik Çalışmalar etik kurulundan izin alındı (Tarih: 26 Haziran 2018 ve No: 2018-12/5). 
quality of life value $(\mathrm{r}=0.176, \mathrm{p}=0.013)$. While there was a significant positive correlation $(\mathrm{r}=0.147$, $\mathrm{P}=0.038$ ) between sitting value and emotional reaction that is one of the sub-parameters of quality of life; a significant negative correlation ( $\mathrm{r}=-0.145, \mathrm{p}=0.040$ ) was found between pain and sitting value.

Conclusions: In this study, the relationship between health-related quality of life and physical activity, pain, and sedentary behavior factors came to the fore.

Keywords: Students, sedentary behavior, quality of life.

\section{Giriş}

Fiziksel aktivite bir pozitif sağlık göstergesi olarak düşünülmelidir. Aslında toplum tarafından sağlıklı yaşam olarak adlandırılan kavramların içerisinde fiziksel aktivite yer almaktadır. ${ }^{1}$ Ülkelerin gelişiminde ve ilerlemesinde dahi toplum sağlığı politikalarının şekillenmesinde fiziksel aktivitenin bir sağlık davranışı şekli olarak karşımıza çıktığı bilinmektedir. Fiziksel aktivite aynı zamanda tüm dünyaya sağlığı hatırlatan araçlardan bir tanesidir. Sadece biyolojik manada değil psikososyal anlamda da fiziksel aktivite potansiyel sağlığı artırmaktadır ${ }^{1-3}$.

Dünya Sağlık Örgütü (DSÖ), iyi sağlı̆̆ı korumak ve geliştirmek için biyolojik olarak minimum sürede ve sıklıkta fiziksel aktivite düzeyini yayınlamıştır4. Tüm bunlara karşı halen sedanter yaşam tarzının daha çok tercih edildiği görülmektedir. Konforlu bir yaşam ve enerji harcanılmasından kaçınıldı $\breve{g}$ bir yaşam stilinin varlığı devam etmektedir. Dolayısı ile modern yaşamın geliştirilmesi ile ilgili faktörlerden bir tanesinin kültür olduğu açık olarak görülmektedir.

Dünyada her 5 kişiden biri fiziksel olarak inaktif yaşamı tercih etmiştir. Bu demektir ki bireyler DSÖ tarafından önerilen belirli fiziksel aktivite miktarını yerine getirememektedirler. Sedanter davranış şekli ise hareketsiz olmayı ancak bilişsel olarak aktif durumu ifade etmektedir. Ekrana maruz kalmak bunlardan biri olarak karşımıza çıkmaktadır. İnaktif yaşam ve sedanter davranış şeklinin bir araya gelmesi ile ciddi sağlık problemleri ortaya çıkabilmektedir. Bilinmektedir ki teknolojinin gelişimi ile birlikte ekran maruziyetinde artış görülmüştür. Sedanter davranış miktarındaki bu büyüme yaşanılan bölgenin gelişim seviyesi ve toplumların refahı ile ilgilidir ${ }^{1-3}$. İnaktivitenin yaş ile arttığı ve özellikle kadınlarda görüldüğü bilinmektedir. Gençlerin beşte biri ve yetişkinlerin 3'te birinin önerilen fiziksel aktivite seviyesine erişemediği literatürde belirtilmiştir5. Araştırmalara göre bilgisayar ekranı ya da televizyon ekranı karşısında geçirilen boş zamanın miktarı sistematik olarak artmakta ve sağlıkla ilgili yaşam kalitesini olumsuz etkilemektedir. Bunun üzerine fiziksel aktivitenin yokluğu eklenince durum daha negatif bir hal almaktadır ${ }^{1,6}$.

Yetişkinlik döneminde bireylerin fiziksel aktivite seviyeleri belirlenmelidir. Tam bu dönemlerde bireylerin sağlık alışkanlıklarının oluştuğu bilinmektedir7. Dolayısı ile tam yetişkinliğe geçiş dönemi olan üniversite çağındaki alışkanlıkların araştırılması ve bireylerin yönlendirilmesi önem taşımaktadır. Üniversite dönemi, bireylerin anne- baba ile yaşamlarından ayrıldı̆̆ı, kendi başına sorumluluk aldıkları bir geçiş dönemidir. Ayrıca bu dönemde konaklama ulaşım gibi tercihler kendilerine kalmadığı için adaptasyon süresi yaşadıkları bir zaman dilimidir8-10. Bu dönemdeki ihtiyaçlar belirlenmeli ve gençlere destek olunmalıdır. Alanda yapılan çalışmalar değer kazanmaktadır. Bu durum çalışmamızın önemini artırmaktadır. Bununla birlikte kazanılan sağlıklı yaşam tarzına fiziksel aktivitenin eklenmesi gelecekte bireyin yaşam kalitesini de etkileyecektir ${ }^{1}$.

Yaşam kalitesi kavramı sosyo- ekonomik ve kültürel gelişimi kapsamaktadır ${ }^{11-14}$. Önceki çalışmalarda fiziksel aktivite ve yaşam kalitesinin birçok parametresi arasında ilişki olduğu 
bulunmuştur15. Bununla birlikte, bu çalışmaların çoğu ya yaşlı, kronik hastalığı olan bireylerde uygulanmıştır ya da yaşam kalitesini değerlendiren ölçekler sağllk değil sosyal içerikli olmuştur. Bununla birlikte çalışmaların çoğu sadece fiziksel aktivite ile yaşam kalitesini değerlendirmiştir ${ }^{12-}$ 15. Bu çalışmada ise fiziksel aktivite ve sağlıkla ilgili yaşam kalitesi parametreleri tek tek incelenmesi, aynı zamanda sedanter davranış ile değerlendirilmesi planlanmıştır.

Yaşam memnuniyeti bireyin kendi başarıları ve kıstas ölçütleri ile ilgilidir. Bireyler bu değerlendirmelere göre kendilerini pozitif ya da negatif olarak eleştirmektedirler. ${ }^{1}$ Literatür incelendiğinde fiziksel aktivite ve yaşam memnuniyeti arasında pozitif ilişki olduğu belirtilmesine rağmen aksini iddia eden çalışmaların olduğu görülmektedir ${ }^{1,10,11,16}$. Nowak ve ark.' nın 2019 yılında yaptıkları çalışmada üniversite öğrencilerinde yaşam kalitesi ile fiziksel aktivite ve sedanter davranış arasında ilişki bulunmamıştır. ${ }^{1}$ Ancak konu ile ilgili araştırmaların önemli olduğu; fiziksel aktivite ve yaşam kalitesinin öğrencinin kültürüne ve bulunduğu yere göre değiştiği vurgulanmıştır.

$\mathrm{Bu}$ çalışmanın amacı, üniversite öğrencileri arasında fiziksel aktivite düzeyi, sedanter davranış ve sağlıkla ilgili yaşam kalitesi arasındaki ilişkinin araştırılmasıdır.

\section{Gereç ve Yöntem}

Çalışma örneklemini, bir devlet üniversitesinde yer alan 200 öğrenci oluşturmaktadır. Kesitsel tipte yapılan bu çalışmada katılımcıların \%70,5’i kadın; \%29,5’i ise erkek bireylerden oluşmaktadır. Çalışma, Helsinki Bildirgesi ilkelerine uygun olarak gerçekleştirilmiş olup, araştırmanın yapılabilmesi için Uludağ Üniversitesi Girişimsel Olmayan Klinik Çalışmalar etik kurulundan izin alındı (Tarih: 26 Haziran 2018 ve No: 2018-12/5). Çalışmaya başlamadan önce katılımcılara, çalışmanın konusu ve amacına yönelik bilgilendirme yapıldı. Bilgilendirilmiş olur formu katılımcılara imzalatıldı. Çalışmaya dâhil edilme kriterleri: İlgili devlet üniversitesinde öğrenci olmak, çalışmaya gönüllü olmak, fiziksel aktivite yapmasına engel son 6 ay içerisinde cerrahi durum olmaması. Çalışmadan dışlama kriterleri: Gönüllü olmamak ve İlgili devlet üniversitesinde öğrenci olmamak, son 6 ay içerisinde fiziksel aktivite yapmasına engel cerrahi geçirilmiş olması.

Bu çalışmada bireylerin Vücut Kütle İndeksi (VKİ) belirlemek için boy ve kilo ölçümü, Bel Kalça Oranı (BKO) belirlemek için bel ve kalça çevre ölçümü alındıktan sonra kas iskelet sistemlerine ait ağrı şiddetini belirlemek için Görsel Ağrı Ölçeği (GAÖ), fiziksel aktivite düzeylerini ölçmek için Uluslararası Fiziksel Aktivite Anketi (UFAA)-kısa form, Sağlıkla ilgili yaşam kalitelerini değerlendirmek için ise Notthingham Sağlık Profili (NSP) kullanılmıştır.

VKİ ve BKO Belirlenmesi: Vücut ağırlığının ( $\mathrm{kg}$ ) boy uzunluğunun karesine $\left(\mathrm{m}^{2}\right)$ bölünmesi ile VKİ değeri belirlenmiştir. VKİ değerleri $18,5 \mathrm{~kg} / \mathrm{m}^{2}$ den az ise zayıf, $\geq 18,5^{-}<24,9 \mathrm{~kg} / \mathrm{m}^{2}$ arasında ise normal, $\geq 25 \cdot 0-<29,9 \mathrm{~kg} / \mathrm{m}^{2}$ arasında ise kilolu olarak sınıflandırılmıştır ${ }^{17}$.

Bel çevresi, ayaktayken iliak çıkıntı ile en alt kaburga arasında belin en ince yerinden ölçülmüştür. Kalçanın en geniş kısmının çevre ölçümü ile kalça çevre ölçümü tamamlanmıştır. Bel çevresinin kalça çevresine bölünmesi ile BKO belirlendi. BKO kesim noktası, erkeklerde $\geq 0,90 \mathrm{~cm}$, kadınlarda ise $\geq 0,85 \mathrm{~cm}^{18}$.

Notthingham Sağlık Profili-(NSP): Bu çalışmada sağlıkla ilgili yaşam kalitesini değerlendirmek için Notthingham Health Profile' nin Türkçe versiyonu kullanılmıştır. Anket, 38 maddeden oluşmakta ve yaşam kalitesine ait enerji (3 madde), ağrı (8 madde), emosyonel reaksiyonlar (9 madde), uyku (5 madde), sosyal izolasyon (5 madde), fiziksel aktivite (8 madde) den oluşan altı 
boyutu değerlendirmektedir. Her bir bölüme o-10o arası puanlama yapılmaktadır. "o" en iyi sağllk durumunu göstermekteyken, 100 en kötü sağllk durumunu ifade etmektedir ${ }^{19}$.

Uluslararası Fiziksel Aktivite Anketi (UFAA)-kısa form: Ölçek, 15-65 yaş arasındaki bireylerin fiziksel aktivite düzeylerini belirlemek amacıyla geliştirilmiştir. UFAA Kısa Form'un Türkiye'de geçerlilik ve güvenilirlik çalışması Savcı ve ark. (2006) tarafından yapılmıştır. Bütün aktivitelerin değerlendirilmesinde her bir aktivitenin tek seferde en az $10 \mathrm{dk}$ yapıllyor olması ölçüt alınmaktadır. Dakika, gün ve MET değeri çarpılarak "METdakika/hafta" olarak bir skor elde edilmektedir. <600 MET-dk/hafta değerinde fiziksel aktivite, düşük; 600-300o MET-dk/hafta değerinde fiziksel aktivite, orta ve $>3000$ MET-dk/hafta değerinde fiziksel aktivite, yüksek olarak sınıflanmıştır. Oturmaya ait soru sedanter aktiviteyi tanımlayıcı olarak kullanıldı ${ }^{8}$.

\section{İstatistik Analiz}

Çalışma sonucunda elde edilen verilerin analizi SPSS (Statistical Packet for The Social Science) 22.o bilgisayar programında yapıldı. Elde edilen verilere dair tanımlayıcı istatistiksel yöntemler, frekans (n), yüzde (\%), ortalama \pm standart sapma, min (minimum) - max (maksimum) olarak verildi. Spearman korelasyon analizi ile niceliksel parametreler arasındaki ilişki test edildi. Korelasyon katsayısı (r) değerleri; 0.00-0.25 arası çok zayıf, 0.26-0.49 arası zayıf, 0.50-0.69 arası orta derecede, 0.70-0.89 arası yüksek derecede, 0.90-1.0 arası çok yüksek derecede ilişki olarak sinıflandırıldı. Kolmogorov-Smirnov normallik testi ile verilerin normalliği kontrol edildi. Tüm analizler \%95 güven aralığında yapıldı. İstatistiksel anlamlılık düzeyi $\mathrm{p}<0.05$ olarak kabul edildi.

\section{Bulgular}

Bireylerin sosyodemografik özelikleri Tablo 1'de gösterilmiştir.

Tablo 1. Demografik özelliklerin gösterimi

\begin{tabular}{|l|l|l|l|}
\hline Kategoriler & & Ortalama \pm Standart Sapma & Minimum-Maksimum \\
\hline Yaş (yıl) & & $19,18 \pm 1,52$ & $17-27$ \\
\hline VKI (kg/m²) & & $21,30 \pm 2,91$ & $15,40-33,06$ \\
\hline BKO (cm) & & $0,78 \pm 0,09$ & $0,35^{-} 1,41$ \\
\hline NSP toplam & & $85,86 \pm 94,10$ & $0-414,08$ \\
\hline UFAA toplam & & $2772,82 \pm 2791,92$ & $0-17952,00$ \\
\hline Oturma & & $399,99 \pm 107,43$ & $120-720,00$ \\
\hline Cinsiyet & & & \\
\hline & Kadın & $141(\% 70,5)$ & \\
\hline & Erkek & $59(\% 29,5)$ & \\
\hline UFAA Sınıflama & & & \\
\hline & Düşük & $26(\% 13)$ & \\
\hline & Orta & $108(\% 54)$ & \\
\hline & Yüksek & $66(\% 33)$ & \\
\hline
\end{tabular}

*VKİ: Vücut Kütle İndeksi, BKO: Bel kalça oranı, NSP: Nottingham Sağlık Profili, UFAA: Uluslararası fiziksel aktivite anketi kısa form

Çalışmada yer alan bireylerin yaş ortalaması 19,18 $\pm 1,52$ yıl olarak bulunurken, vücut kütle indeks (VKİ) ortalaması ise $21,30 \pm 2,91 \mathrm{~kg} / \mathrm{m}^{2}$ olarak bulundu. Toplam katılımcı sayısı 200 olmakla birlikte bireylerin 141' i $(\% 70,5)$ kadın, 59' u $(\% 29,5)$ erkeklerden oluşmaktadır. Bireylerin toplam fiziksel aktivite ortalaması 2772,82 $\pm 2791,92$ MET-dk/Hafta olarak belirlendi. UFAA_kısa form 
sinıflamasına göre bireylerin \%13' ü düşük fiziksel aktivite düzeyine sahipken, \%54' ü orta, \%33’ ü yüksek fiziksel aktivite düzeyine sahip olduğu bulundu.

Tablo 2' de fiziksel aktivite, sedanter davranış (SD) ve yaşam kalitesi parametreleri arasında ilişki analizi sonuçları gösterilmiştir. Fiziksel aktivite toplam değeri ile yaşam kalitesi toplam değeri ( $\mathrm{r}=$ $0,176, p=0,013)$, yaşam kalitesi alt parametrelerinden emosyonel reaksiyonlar $(\mathrm{r}=0,170, \mathrm{p}=$ o,016) ve uyku ( $\mathrm{r}=0,272, \mathrm{p}=0,000)$ arasında pozitif yönde anlamlı ilişki bulundu (Tablo 2). Sedanter davranış olarak tanımlanan fiziksel aktivite alt parametrelerinden oturma değeri ile yaşam kalitesi alt parametrelerinden emosyonel reaksiyon arasında pozitif yönde anlamlı ilişki $(\mathrm{r}=0,147, \mathrm{P}=0,038)$ bulunurken; oturma değeri ile ağrı arasında negatif yönde anlamlı ilişki ( $\mathrm{r}=$ $-0,145, p=0,040$ ) bulundu (Tablo 2). Ağrı ile yaş ( $r=0,149, p=0,035)$, yaşam kalitesi toplam değeri $(\mathrm{r}=0,350, \mathrm{p}=0,000)$ ile yaşam kalitesi alt parametrelerinden enerji seviyesi $(\mathrm{r}=0,315, \mathrm{p}=0,000)$, ağrı $(\mathrm{r}=0,330, \mathrm{p}=0,000)$, emosyonel reaksiyon $(\mathrm{r}=0,309, \mathrm{p}=0,000)$, sosyal izolasyon $(\mathrm{r}=0,259$, $\mathrm{p}=0,000)$, uyku $(\mathrm{r}=0,154, \mathrm{p}=0,030)$, fiziksel aktivite $(\mathrm{r}=0,250, \mathrm{p}=0,000)$ arasında pozitif yönde istatistiksel olarak anlamlı ilişki bulundu (Tablo 2). Yaşam kalitesi toplam değeri ile BKO arasında ise negatif yönde istatistiksel olarak anlamlı ilişki bulundu ( $\mathrm{r}=-0,144, \mathrm{p}=0,042)$ (Tablo 2).

Tablo 2. Fiziksel aktivite, sağlıkla ilgili yaşam kalitesi, sedanter davranış ve diğer kategoriler arasındaki ilişkinin gösterimi

\begin{tabular}{|c|c|c|c|c|c|c|c|c|c|c|c|c|c|c|}
\hline \multirow[t]{2}{*}{ Kategoriler } & & \multirow[b]{2}{*}{ Yaş } & \multirow[b]{2}{*}{ vKi } & \multirow[b]{2}{*}{ Вко } & \multirow[b]{2}{*}{ GAÖ } & \multirow{2}{*}{$\begin{array}{l}\text { UFAA } \\
\text { TOPLAM }\end{array}$} & \multirow{2}{*}{$\begin{array}{l}\text { NIIP } \\
\text { ES }\end{array}$} & \multirow{2}{*}{$\begin{array}{l}\text { NIIP } \\
\Lambda\end{array}$} & \multirow{2}{*}{$\begin{array}{l}\text { NIIP } \\
\text { ER }\end{array}$} & \multirow{2}{*}{$\begin{array}{l}\text { NIIP } \\
\text { SE }\end{array}$} & \multirow{2}{*}{$\begin{array}{l}\text { NIIP } \\
\mathrm{U}\end{array}$} & \multirow{2}{*}{$\begin{array}{l}\text { NIIP } \\
\text { FA }\end{array}$} & \multirow{2}{*}{$\begin{array}{l}\text { NIIP } \\
\text { TOPLAM }\end{array}$} & \multirow[t]{2}{*}{ SD } \\
\hline & & & & & & & & & & & & & & \\
\hline \multirow[t]{2}{*}{ Yaş (Yil) } & $\mathbf{r}$ & 1,000 &,- 034 &,- 040 &, 149 & ,082 &, $212^{*}$ &, $193^{2}$ &, $249^{* *}$ &, $211^{*}$ &, $225^{*}$ & $290^{* *}$ &, $308^{* 8}$ &, 037 \\
\hline & $\mathbf{p}$ & . &, 636 &, 577 & 035 &, 250 &, 003 & ,006 &, 000 & 003 & 001 & 000 & , 000 & 607 \\
\hline \multirow[t]{2}{*}{ VKİ (kg/m²) } & $\mathrm{r}$ & 1,000 & &, $223^{\text {th }}$ &,- 019 & ,079 &,- 048 &, 032 &,- 093 &,- 029 &, 070 &,- 023 &,- 027 &,- 077 \\
\hline & p & & &, 002 &, 794 &, 265 &, 500 & ,653 & 192 &, 679 &, 322 &, 750 & 699 &, 277 \\
\hline \multirow[t]{2}{*}{ Bel Kalça oranı (cm) } & $\mathbf{r}$ & 1,000 & & & 097 & 057 &,$- 172^{*}$ &,$- 252^{* *}$ &,$- 172^{\circ}$ &,- 107 &,- 064 &,$- 187^{* *}$ &,$- 144^{+*}$ &,- 028 \\
\hline & p & & & &, 171 &, 424 &, 015 & 000 & 015 & 133 &, 369 & 008 &, 042 & 691 \\
\hline \multirow[t]{2}{*}{ GAÖ (cm) } & $\mathrm{r}$ & 1,000 & & & &,- 096 &, $315^{2 *}$ &, $330^{2 * t}$ &, $309^{* *}$ &, $259^{+8}$ & 154* &, $250^{2+5}$ &, $350^{+2}$ &,$- 145^{*}$ \\
\hline & p & & & & &, 175 &, 000 &, 000 &, 000 &, 000 &, 030 &, 000 &, 000 &, 040 \\
\hline \multirow[t]{2}{*}{ UFAA TOPIAAM } & $\mathbf{r}$ & 1,000 & & & & &,- 019 &,- 013 &, $170^{*}$ &, 064 &, $272^{* 8}$ &, 065 & ,176* & 039 \\
\hline & $\mathbf{p}$ & . & & & & &, 790 & 854 &, 016 & 369 & ,000 &, 361 & ,013 &, 579 \\
\hline \multirow[t]{2}{*}{ NSP ES } & $r$ & 1,000 & & & & & & $.532^{k+1}$ & $.583^{3 *}$ &, $509^{\text {** }}$ &, $396^{=8}$ & $.503^{2 *}$ &, $776^{\star 8}$ &, 001 \\
\hline & p & & & & & & &, 000 &, 000 &, 000 &, 000 &, 000 & , 000 &, 994 \\
\hline \multirow[t]{2}{*}{ NSP A } & $\mathbf{r}$ & 1,000 & & & & & & &, $425^{* *}$ & $297^{*}$ & $298^{* *}$ &, $553^{* *}$ &, $594^{* *}$ &,- 032 \\
\hline & p & . & & & & & & &, 000 &, 000 &, 000 &, 000 &, 000 & 649 \\
\hline \multirow[t]{2}{*}{ NSP ER } & $r$ & 1,000 & & & & & & & &, $630^{* *}$ &, $547^{* *}$ &, $441^{* *}$ &, $170^{n *}$ &, $147^{*}$ \\
\hline & p & & & & & & & & &, 000 & ,000 & 000 & ,016 & ,038 \\
\hline \multirow[t]{2}{*}{ NSP_Sİ } & $\mathbf{r}$ & 1,000 & & & & & & & & &, $453^{* *}$ & $384^{* *}$ & $688^{* *}$ &, 068 \\
\hline & $\mathbf{p}$ & . & & & & & & & & & , 000 & , 000 & , 000 &, 338 \\
\hline
\end{tabular}

*VKİ: Vücut Kütle İndeksi, BKO: Bel kalça oranı, GAÖ: Görsel ağrı ölçeği, UFAA: Uluslararası fiziksel aktivite anketi kısa form, NSP: Nottingham Sağlık Profili, ES: Enerji, A: Ağrı, ER: Emasyonel reaksiyon, SE: Sosyal izolasyon, U: Uyku, FA: Fiziksel aktivite, SD: Sedanter davranış 


\section{Tartışma}

Bu çalışmada üniversite öğrencilerinde fiziksel aktivite düzeyi, sedanter davranış ve sağlıkla ilgili yaşam kalitesi arasındaki ilişkinin tanımlanması hedeflenmiştir. İnsan sağlı̆̆ında yaşam kalitesi, fiziksel aktivitenin ideal şartlarda sürdürülebilmesi için öncelikli olması gereken alanlardandır. Fiziksel aktivitenin faydaları bilinmektedir. Ancak ideal bir yaşam kalitesi sağlandığında fiziksel aktivite için koşulların oluşabileceği bilinmektedir²0,21. Fiziksel aktivite ile ilgili yayınlar 1980’lere kadar dayanmakla birlikte toplumlarda halen yeterli düzeyde fiziksel aktivite yapılmadığı belirlenmiştir ${ }^{12,22}$. Bununla birlikte her toplumun kendine özgü fiziksel aktivite rehberi oluşturduğu bilinmektedir. Fiziksel aktivitenin toplumların ekonomik, sosyal ve çevresel koşullarından etkilendiği bilinmektedir ${ }^{15}$.

Türkiye'de üniversite öğrencileri olarak daraltılan çalışma alanında literatür araştırıldığında, üniversite öğrencilerinin fiziksel aktivite değerleri benzer bulunmaktadır. Ancak halen ideal orta düzeyde düzenli fiziksel aktivite seviyesinin yaygınlaşmadığı görülmektedir ${ }^{2,3,8}$. Ülkemiz T.C. Sağlık Bakanlığı Türkiye Halk Sağlığı Kurumu tarafından 2014 yılında yayımlanan fiziksel aktivite rehberine göre hiç egzersiz yapmayanların oranı 19-30 yaş grubunda \%69,5, 19-30 yaş grubunda \%76.6 olarak gözlenmiştir3. Pirinçci ve ark.' nın 2020 yılında yaptıkları çalışmada 192 üniversite öğrencisinin \%9'unun fiziksel olarak aktif olmadığı, \%59'unun düşük seviyede aktif olduğu, \%32'sinin de yeterli seviyede aktif olduğu bulunmuştur ${ }^{2}$. Savcı ve ark.' 1 çalışmalarında, öğrencilerin fiziksel aktivite düzeylerinin \%15' inin inaktif, \% 68'inin minimal aktif, \% 18'inin çok aktif olduklarını belirtmişlerdir8 ${ }^{8}$. Bu çalışmada ise hafif düzeyde fiziksel aktivite oranı \%13, orta düzeyde \%54, şiddetli düzeyde ise \%33 bulunmuştur. Çalışmamız sonuçları literatür ile uyumludur. Bununla birlikte inaktif birey oranı bu çalışmada yer almamaktadır. Bu sonuç öğrencilerimizin fiziksel olarak aktif kalmaya çalıştığının sevindirici bir özelliği olarak karşımıza çıkmaktadır. Dahası çalışmaların yapıldığı sosyal çevre ve öğrencilerin ekonomik durumunun da bu sonuçlar üzerinde etkili olması beklenmektedir²3. Ancak bu çalışmada sosyo-ekonomik düzeye yönelik değerlendirme yapılmamıştır.

VKI' nin ve yaşam kalitesinin fiziksel aktivite düzeyi ile ilişkisi olduğu önceki çalışmalarda belirtilmiştir'. Bu çalışmada VKİ değerleri normal sınırlar içerisindedir. Bel kalça oranı da bu çalışmada değerlendirilmiştir. Dahası yaşam kalitesi toplam değerleri ile BKO arasında negatif ilişki bulunmuştur. Bilinmektedir ki bireylerin ağırlıkları ve sağlıkları arasındaki yorum yapmada başlıca kullanılan iki değer VKİ ve BKO'dır. Bu iki değerin birlikte değerlendirilmesi gerekmektedir ${ }^{17,18}$. Ortalama değerler normal sınırlarda iken VKİ' nin yaşam kalitesi ile ilişkili olmaması, BKO’daki artışla yaşam kalitesi arasında bulunan negatif ilişkinin örneklem sayısının az olması ile ilişkili olabileceği düşünülmektedir.

Bu çalışmada yaş ve ağrı değerleri arttıkça bireylerin yaşam kalitelerinin olumsuz etkilendiği belirlenmiştir. Söz konusu bu faktörler birçok çalışmada yaşam kalitesi ile ilişkili bulunmuştur ${ }^{1,2,14,15}$. Yaş ilerledikçe üniversite öğrencisinin sosyo-ekonomik durumunun ya da duygu durumunun değişebileceği dolayısı ile yaşam kalitesinin azabileceği belirtilmiştir ${ }^{23}$. Bununla birlikte ağrı sadece yaşam kalitesi toplam değerleri ile değil tüm alt parametreler ile de pozitif yönde ilişkili bulunmuştur. Ağrı arttıkça bireyin duygu durumunun, fonksiyonelliğinin ve sosyalliğinin azaldığı söylenebilir. Ağrının bireyin psiko- sosyal durumu ile ilişkili olduğu çalışmalarda belirtilmiş̧tir. Bu çalışmada da yaşam kalitesinin ağrıdan olumsuz etkilenebileceği bulunmuştur. Gelecekte daha büyük örneklemler ile ağrı şiddeti ve yeri sorgulanarak çalışmanın tekrarlanması önerilmektediri12,23.

$\mathrm{Bu}$ çalışmada yaşam kalitesi ile fiziksel aktivite düzeyi arasında pozitif ilişki bulunmuş; fiziksel aktivite şiddeti arttıkça yaşam kalitesi değerlerinin olumsuz yönde ilerlediği belirlenmiştir. Bu 
durum literatür ile uyumludur ${ }^{11}$. Fernandez ve ark.'ina göre fiziksel aktivitenin şiddeti ile yaşam kalitesi arasında ilişki net olarak literatürde yer almamaktadır. Burada kullanılan ölçeklerin gerçekten yaşam kalitesini değerlendirebileceği de eleştirilmektedir. Yaşam kalitesi faktörlerinden bir tanesi psikososyal durum. Bu durumda anketle yapılan ölçümlerin gerçekten kişinin özellikle psikolojik durumunu yansıtıp yansıtmadığı da araştırma konusu olmuştur 13,24,25. $\mathrm{Bu}$ çalışmada yaşam kalitesi alt parametrelerinden uyku ve emosyonel reaksiyonlar ile de ilişkili bulunmuş ve fiziksel aktivite arttıkça uyku ve emosyonel reaksiyonların olumsuz etkilenebileceği düşünülmüştür. Ëjsvogels ve ark.'nın 2018 yllında yaptıkları çalışmada şiddetli fiziksel aktivitenin bireyin sağlığını aritmi gibi kardiyovasküler riskler nedeniyle olumsuz etkileyebileceği belirtmişlerdir ${ }^{16}$. Bu çalışmada şiddetli fiziksel aktivite oranı \%33'dür. Bu oranın sonuçları etkilemiş olabileceğini düşünüyoruz. Literatürde şiddetli fiziksel aktivitenin negatif ve pozitif

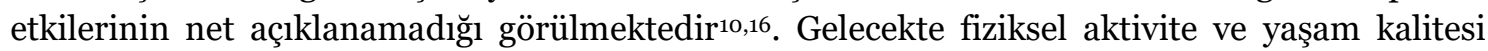
arasındaki ilişki araştırılırken ayrı bir ölçekle psiko-sosyal durumun değerlendirilmesini öneriyoruz.

Sedanter davranış şekli birçok yayında kronik hastalıkların sebebi olarak yer almaktadır ${ }^{14}$. Obezite ve hareketsiz yaşam özellikle üniversite öğrencilerinde teknolojinin etkisi ile yaygınlaşmaktadır ${ }^{14,26}$. Bu çalışmada UFAA_kısa form da yer alan oturma süresi sedanter davranış olarak nitelendirildi ve analizler yapılmıştır. ${ }^{1}$ Sedanter davranış arttıkça ağrı ve emosyonel reaksiyonların olumlu yönde azaldığı ilişkisi bulunmuştur. Literatürde sedanter davranışın sağlık üzerine etkisi henüz netleştirilmemiştir ${ }^{26}$. Bunun en önemli sebebi olarak sedanter aktivitenin değerlendirilme metodunun çalışmalardaki farklılığı olarak belirtilmektedir. $\mathrm{Bu}$ çalışmada da oturma süresi sedanter davranış olarak kabul edildiğinden ve fiziksel olarak inaktif birey olmadığından, sedanter davranış bu çalışmada bireyin dinlenme süresi olarak yorumlanabilir27. Bu sayede bireyin kendine ayırdığı dinlenme süresi ile kas iskelet sistemi ağrlarında azalma ve emasyonel reaksiyonlarda olumlu yönde etkilenme görülmesi ihtimali olduğu söylenebilir. Ayrıca bu çalışmada yer alan bireylerin BKO ve VKI'leri de normal sınırlar içerisinde olmakla birlikte bireylerde kas iskelet sistemine yönelik ağrı ile yaşam kalitesi toplam ve alt parametreleri arasındaki ilişki dikkat çekiciydi. Dolayısı ile bu çalışma sonucunda üniversite öğrencilerinde sedanter davranıştan daha fazla kas iskelet sistemine yönelik ağrıların yaşam kalitesi üzerine etkili olabileceği düşünülmektedir.

Üniversitede cep telefonu, bilgisayar gibi teknolojik aletlerin sık kullanılması, bireyin yurtta yaşaması nedeniyle kullandığı sandalye ve masanın ergonomisinin uyumsuz olması gibi faktörlerin öğrencilerde ağrı ortaya çıkarabileceği literatürde belirtilmiştir ${ }^{28}$. Dolayısı ile öğrencilerde sedanter davranıştan daha çok ağrı değerlendirmelerinin yapılmasına ve duruş ve ergonomik bilgilerin yer aldığı eğitim programlarının düzenlenmesini öneriyoruz. Ayrıca üniversitelere ve yurt yönetimlerine de özel görevler düştügüünü düşünüyoruz. Öğrencinin ders çalışması ya da dinlemesi esnasında vücut kompozisyonuna uygun sıra-masa seçme imkânının oluşturulabileceği, fiziksel aktiviteye imkân tanıyan sosyal alanların kampüs içerisinde yer alabileceğini düşünüyoruz.

Baş ve ark.'nın 2007 yılında yaptıkları çalışmalarında enerji harcaması ve fiziksel aktivite ilişkili bulunmuş, sedanter davranışın sağllğı olumsuz etkileyebileceği belirtilmiştir29. Aynı şekilde Yılmaz ve Karaca' nin 2019 yılında üniversite öğrencilerinde yaptıkları çalışmalarında sedanter davranışların sağlıklı yaşam ve yaşam kalitesi üzerine olumsuz etkileri olduğu belirtilmiştir30. Bu çalışmada ise inaktif birey bulunmadı. Bireylerin hepsi fiziksel olarak aktifti. Bu çalışmada ağrı ile sedanter davranış arasında negatif bir ilişki bulunmuştur. Sedanter davranışın ağrı ile ilişkisinin net olmadığı literatürde belirtilmiştir. Dolayısı ile çalışmamızda bulunan bu negatif ilişki, üniversite öğrencilerinde görülmesi beklenmeyen bir durum olmakla birlikte teknolojik 
yaşam, bireyin yurtta yaşaması nedeniyle kullandığı sandalye ve masanın ergonomisinin uyumsuz olması gibi faktörlerin öğrencilerde ağrı ortaya çıkarabileceği literatürde belirtilmiştir ${ }^{28}$. Dolayısı ile öğrencilerde sedanter davranıştan daha çok ağrı değerlendirmelerinin yapılmasına ve duruş ve ergonomik bilgilerin yer aldığı eğitim programlarının düzenlenmesini öneriyoruz. Ayrıca üniversitelere ve yurt yönetimlerine de özel görevler düştügüüü düşünüyoruz. Öğrencinin ders çalışması ya da dinlemesi esnasında vücut kompozisyonuna uygun sıra-masa seçme imkânının oluşturulabileceğini düşünüyoruz.

$\mathrm{Bu}$ çalışma tanımlayıcı tipte bir çalışma olduğundan elde edilen veriler tüm üniversite öğrencilerini kapsamamaktadır. Ayrıca söz konusu veriler ile neden sonuç ilişkisi kurulamamaktadır. Bu durum çalışmanın kısıtlılığı olmakla birlikte zaten literatürde şehirlere ve üniversitelere göre elde edilen sonuçların değișeceği belirtilmektedir ${ }^{15}$.

\section{Sonuç}

$\mathrm{Bu}$ çalışmanın amacı, üniversite öğrencileri arasında fiziksel aktivite düzeyi, sedanter davranış ve sağlıkla ilgili yaşam kalitesi arasındaki ilişkinin araştırılmasıdır. Bu çalışmada sağlıkla ilgili yaşam kalitesi ile fiziksel aktivite ve ağrı faktörleri arasındaki ilişki ön plana çıkmıştır. Üniversite öğrenciler kısıtlı bir çevrede ve sürede kendilerine yaşanabilir ortam oluşturmaya çalışan bir topluluk olarak gözlemlenmektedir. Sağllkla ilgili yaşam kalitesi parametresi üniversite öğrencilerinde hem kendi fiziksel koşulları hem de sosyo-ekonomik koşullarına bağlı değişebilmektedir. Özellikle ağrı değerlendirmesinin üniversite öğrencilerinde sağlıkla ilgili yaşam kalitesi değerlendirmeleri yapılırken kullanılmasını öneriyoruz.

\section{KAYNAKLAR}

1. Nowak PF, Bożek A, Blukacz M. Physical activity, sedentary behavior, and quality of life among university students. Biomed Res Int. 2019;2019:9791281.

2. Pirinççi SC, Cihan E, Ün YN. Üniversite öğrencilerinde fiziksel aktivite düzeyinin yaşam kalitesi, kronik hastalık varlığı, sigara kullanımı ve akademik başarıyla olan ilişkisi. KTO Karatay Üniversitesi Sağllk Bilimleri Dergisi. 2020;1(1):15-23.

3. T.C. Sağlık Bakanlığı. Türkiye Halk Sağlığı Kurumu Türkiye Fiziksel Aktivite Rehberi. 2. baskı. Ankara: Kuban Matbaacılık Yayıncılık; 2014. ISBN: 978-975-590-492-4.

4. World Health Organization. WHO guidelines on physical activity and sedentary behaviour. WHO. https://www.who.int/teams/health-promotion/physical-activity/developingguidelines-on-physical-activity-and-sedentary-behaviour. Erişim tarihi o6 Mart 2020.

5. Hallal PC, Andersen LB, Bull FC, et al. Global physical activity levels: surveillance progress, pitfalls, and prospects. Lancet. 2012;380(9838):247-257.

6. Davies CA, Vandelanotte C, Duncan MJ, van Uffelen JG. Associations of physical activity and screen-time on health related quality of life in adults. Prev Med. 2012;55(1):46-9.

7. Sert A. Tıp fakültesi ve meslek yüksekokulu öğrencilerinde sağlıklı yaşam biçimi davranışları ve etkileyen faktörler. Turk JPH. 2019;17(2):132-142.

8. Savcı S, Öztürk M, Arıkan H, İnce Dİ, Tokgözoğlu L. Physical activity levels of university students. Turk Kardiyol Dern Ars. 2006;34(3):166-172.

9. Kaltum AM. Association Between Physical Activity and Perceived Stress among collegeand University Students: A Quantitative Study From A Public Health Science Perspective. [independent thesis advanced level]. Sweden: Malardalen University, School of Health Care and Social Welfare; 2020. 
10. Costigan SA, Lubans DR, Lonsdale C, Sanders T, Del Pozo Cruz B. Associations between physical activity intensity and well-being in adolescents. Prev Med. 2019;125:55-61.

11. Fernandez AR, Ramos-Diaz E. Quality of life and physical activity: their relationship with physical and psychological well being. Quality of life and physical activity: their relationship with physical and psychological well-being. Quality of Life and Quality of Working Life. 2017;53-70.

12. Grasdalsmoen M, Engdahl B, Fjeld MK, et al. Physical exercise and chronic pain in university students. PLoS One. 2020;15(6):e0235419.

13. Keeley P, Creed F, Tomenson B, et al. Psychosocial predictors of health-related quality of life and health service utilisation in people with chronic low back pain. Pain. 2008;135:142-50.

14. Yllmaz A. Üniversite öğrencilerinde fiziksel aktivite, sedanter süre ve yaşam kalitesi ilişkisinin değerlendirilmesi. OPUS-Uluslararası Toplum Araştırmaları Dergisi. 2019;10(17):1433-1453.

15. Kokic SI, Znika M, Brumnic V. Physical activity, health-related quality of life and musculoskeletal pain among students of physiotherapy and social sciences in Eastern Croatia- Cross-sectional survey. Ann Agric Environ Med. 2019;26(1):182-190.

16. Eijsvogels TMH, Thompson PD, Franklin BA. The "Extreme exercise hypothesis": Recent findings and cardiovascular health implications. Curr Treat Options Cardiovasc Med. 2018;20(10):84.

17. World Health Organisation. Waist circumference and waist-hip ratio: report of a WHO expert consultation. WHO. https://www.who.int/publications/i/item/9789241501491. Yayınlanma tarihi 2011. Erişim tarihi 20 Ekim 2018.

18. World Health Organisation. The international classification of adult underweight, overweight and obesity according to BMI. WHO.

http://www.assessmentpsychology.com/icbmi.htm. Yayınlanma tarihi 2014. Erişim tarihi 20 Ekim 2018.

19. Kücükdeveci AA, McKenna SP, Kutlay S, Gürsel Y, WhalleyD, Arasil T. The development and psychometric assessment of the Turkish version of the Nottingham Health Profile. Int JRehabil Res. 2000;23:31-8.

20. Bozkuş T, Türkmen M, Kul M, Özkan A, Öz Ü, Cengiz C. Beden Eğitimi ve Spor Yüksekokulu'nda öğrenim gören öğrencilerin fiziksel aktivite düzeylerï ile sağlıklı yaşam biçimi davranışlarının belirlenmesi ve ilişkilendirilmesi. IntJSCS. 2013;1(3):49-65.

21. Snedden TR, Scerpella J, Kliethermes SA, et al. Sport and Physical Activity Level Impacts Health-Related Quality of Life Among Collegiate Students. Am J Health Promot. 2019;33(5):675-682.

22. Eaton BS, Konner M, Shostak M. Stone agers in the fast lane: Chronic degenerative diseases in evolutionary perspective. The American Journal of Medicine. 1988;84(4): 739749 .

23. Paananen M, Taimela S, Auvinen J, Tammelin T, Zitting P, Karppinen J. Impact of selfreported musculoskeletal pain on health-related quality of life among young adults. Pain Med. 2011;12(1):9-17.

24. Guite JW, Logan DE, Sherry DD, Rose JB. Adolescents self-perception: Associations with chronic musculoskeletal pain and functional disability. $J$ Pain. 2007;8:379-86.

25. Nicholl BI, Macfarlane GJ, Davies KA, et al. Premorbid psychosocial factors are associated with poor health related quality of life in subjects with new onset of chronic widespread pain results from the EPIFUND study. Pain. 2009;141:119-26. 
27. Chen SM, Liu MF, Cook J, Bass S, Lo SK. Sedentary lifestyle as a risk factor for low back pain: a systematic review. Int Arch Occup Environ Health. 2009;82(7):797-806.

28. Mutz M, Reimers AK. Demetriou Y. Leisure time sports activities and life satisfaction: deeper insights based on a representative survey from Germany. Applied Research Quality Life. 2020. https://doi.org/10.1007/s11482-020-09866-7.

29. Kurtaran M, Baktır S, Abanoz ŞE, Yeldan İ. Üniversite öğrencilerinde ağrı, aleksitimi, depresif belirti yaygınlığı ve yaşam kalitesinin değerlendirilmesi. Sakarya Tıp Dergisi. 2019;9(3):433-441.

30. Baş AU, Livanelioğlu A, Aslan Ş. Fiziksel aktivite düzeyinin üniversite öğrencilerinde iki farklı yöntemle değerlendirilmesi. Fizyoter Rehabil. 2007;18(1):11-19.

31. Yılmaz G, Karaca S. Spor yapan ve sedanter üniversite öğrencilerinin beslenme bilgi tutum ve yaşam kalitelerinin incelenmesi. Niğde Üniversitesi Beden Eğitimi ve Spor Bilimleri Dergisi. 2019;13(3):258-266. 